\title{
PERSEPSI DAN STIGMA PENYANDANG DISABILITAS PADA SISWA-SISWI SEKOLAH MENENGAH ATAS
}

\author{
Dian Permatasari,Ahmad Guntur Alfianto*, Miftakhul Ulfa \\ STIKES Widyagama Husada Malang
}

Corresponding author:

Ahmad Guntur Alfianto

STIKES Widyagama Husada Malang

Email:ahmadguntur@widyagamahusada.ac.id

\begin{abstract}
The People with disabilities can create problems in the school. Schools which have students with disabilities will affect the students around them. Perceptions and stigma are factors in the problems of students, especially schools that accept students with disabilities. The purpose of this study was to analyze the relationship between perceptions and stigma of people with disabilities in senior high school. This study used descriptive correlation design and cross sectional approach with the respondents of senor high school students in Sidoarjo City. The sampling technique used was simple random sampling with sample size of 305 respondents who fill up criteria. The measuring instruments used are self perception with cronbach alpha value of 0.883 and a mental illness scale with cronbach alpha value of 0.783. Bivariate analysis using the chi square test and the result is $p$ value (0.001). So it can be concluded that there is a relationship between perceptions and the stigma of people with disabilities in senior high school.
\end{abstract}

Keywords:perception; stigma; disabilities

\begin{abstract}
Abstrak
Penyandang disabilitas di sekolah menjadikan permasalahan di lingkungan sekolah. Sekolah yang memiliki siswa dengan penyandang disabilitas akan mempegaruhi siswa-siswa di sekitarnya. Persepsi dan stigma adalah faktor dari permasalahan siswa-siswi terutama sekolah yang menerima siswasiswi dengan penyandang disabilitas. Tujuan penelitian ini adalah menganalisis hubungan persepsi dan stigma penyandang disabilitas pada siswa-siswi di Sekolah Menegah Atas (SMA). Penelitian ini menggunakan desain diskriptif korelasi dan pendekatan cross sectional dengan responden siswa-siswi SMA di Kota Sidoarjo. Tekniksampeling yang digunakan adalah simple random sampling dengan jumlah sampel 305 responden yang memenuhi kriteria. Alat ukur yang di gunakan adalah self percaption dengan nilai cronbach alpha0,883 dan mental illness scale dengan nilai cronbach alpha 0,783. Analsis bivariat menggunakan uji chi square dan hasilnya adalah $p$ value $(0,001)$. Sehingga dapat di simpulkan terdapat hubungan antara persepsi dengan stigma penyandang disabilitas siswa-siswi SMA.
\end{abstract}

Kata Kunci: Persepsi; Stigma: disablitias 


\section{PENDAHULUAN}

Penyandang disabilitas atau disebut juga dengan anak berkebutuhan khusus (ABK) adalah seseorang atau anak yang mengalami kelainan secara fisik, mental, intelektual, sosial dan emsional (Fauth et al., 2017). Seseorang dengan disabilitas diantaranya tunanetra, tunarungu, tunadaksa, tunagrahita, tunalaras, kesulitan belajar, ganggun perilaku dan anak denga gangguan kesehatan mental (Aydın, 2015).

Di tahun 2018 hasil Riset Kesehatan Dasar (RISKESDES) Kementerian Kesehatan menyatakan proporsi disabilitas pada umur 5-17 tahun sebesar $3,3 \%$ dan pada umur 18-59 tahun sebesar $22 \%$. Pada umur 60 ke atas 2,6\% mengalami disabilitas berat dan ketergantungan total.42,8\%. Jawa timur menempati urutan ke-11 pada presentase penyandang disabilitas tertinggi di indonesia dengan 9,40 (Kementerian Kesehatan RI Badan Penelitian dan Pengembangan, 2018).

Masyarakat memiliki persepsi berbeda terhadap penyandang disabilitas. Penyandang disabilitas sering mengalami masalah seperti diskriminasi serta pandangan yang kurang baik di masyarakat (Löve et al., 2018). Hal tersebut sama dengan sesorang yang memiliki masalah kesehatan mental juga memiliki perlakuan sama seperti di abaikan atau di tolak di masyarakat (Coston, 2019).

Penolakan dan pengabaian penyadanng disabilitas di masayarakat memunculkan stigma negatif terhadap penyandang disabilitas (Yaqien et al., 2018). Penelitian tentang stigma penyandang disabilitas juga banyak terutama kepada mereka yang mengalami masalah kesehatan mental. Stigma negatif akan muncul pada Keluarga atau orang dengan gangguan jiwa dimasyarakat (Krupchanka et al., 2018).

Hasil studi pendahuluan di sebuah Sekolah Menengah Atas (SMA) di Kota Sidoarjo menunjukkan bahwa terdapat 14 siswa penyandang disabilitas, 9 siswa mengalami keterlambatan belajar, 3 siswa penyandang autisem, 1 siswa penyandang tunarungu, serta 1 siswa penyandang disleksia. Selain fasilitas di SMA tersebut juga memberikan ruang khusus bagi siswa penyandang disabilitas untuk mampu berinteraksi dengan fasilitator ataupun guru ketika belajar.

Dari masalah tersebut di lakukan penelitian pada siswa-siswa di SMA tersebut untuk menganalisis tentang persepsi dan stigma pada siswa dengan penyandang disabilitas. Rumusan masalah pada penelitian ini adalah apakah ada hubungan persepsi dan stigma penyandang disabilitas pada siswa-sisiwi di SMA kota Sidoarko. Selain itu penelitia juga menganasilis hubungan antara persepsi siswa-siswi dengan stigma pada siswa-siswi penyandang disabilitas.

\section{METODE}

Penelitian ini menggunakan metode kuantitatif dengan desain penelitian diskriptif korelasi dan pendekatan cross sectional untuk mengetahui hubungan persepsi dan stigma penyandang disabilitas pada siswa-siswi di SMA kota Sidoarjo. Responden pada penelitian ini adalah siswa-siswi yang terdaftar di salah satu SMA kota Sidoarjo yang menjadi tempat penelitian. Teknik sampling yang di gunakan pada penelitian ini adalah simple random sampling dengan dengan kriteria responden bukan penyandang disabilitas dan atau anak berkebutuhan khusus. Total sampel sebanyak 305 responden.

Alat ukur yang di gunakan pada penelitian ini adalah kuesioner berupa self perception untuk mengukur persepsi responden dengan nilai cronbach alpha pada penelitian sebelumnya 0,81 (Jakobsson et al., 2019). dan mental illness stigmascale pada penelitian sebelumnya memiliki nilai crobcah alpha 0,80 (Caqueo-Urízar et al., 2019). Pada kuesioner self perception memiliki indikatior persepsi positif dan negatif dengan jumlah 52pertanyaan dan hasilnya persepsi baik dan buruk. Sedangkan pada mental illness 
scales stigma indikator keterasingan, pengalaman diskriminasi, dukungan, penarikan sosial serta resistensi stigma dengan jumlah 29 pertanyaan dan hasilnya stigma tinggi dan rendah. Kedua kuesioner tersebut di terjemahkan dan di lakukan uji validitas dan reliabilitas di 30 responden yang hampir mirip dengan responden penelitian di SMA di kota Malang. Hasil cronbach alpha untuk self perception 0, 883 dan Mental illness scale 0,783.

Teknik pengumpulan data di lakukan dengan mengisi kedua kuesioner tersebut melalui googleform yang berisi tentang lembar persetujuan dan kesediaan mengikuti penelitian serta kedua kuesioner tersebut. Kuesioner tersebut di bagi perkelas yang sebelumnya sudah di informasikan oleh guru bimbingan konseling untuk mengisi kuesioner tersebut di grup whatsapp. Kemudian peneliti menyebarkan ke 2 kuesioner tersebut melalui link googleform dan di teruskan ke grup whatsapp kelas oleh peneliti.

Analisis data menggunkan Statistical Package for Servive Solution (SPSS) 20. Uji statistik menggunakan uji univariat dan bivariat. Uji univariat untuk menganalisis karakteristik responden sedangkan uji bivariat menggunkan uji Chi square untuk menganalisis hubungan antara persepsi dan stigma penyandang disabilitas. Penelitian ini mendapatkan persetujuan etik dari komisi etik STIKES dr. Soebandi Jember dengan nomor 58/SDS/KEPK/TL/VI.

\section{HASIL DAN PEMBAHASAN}

Berdasarkan penelitian tentang hubungan persepsi dan stigma penyandang disabilitas pada siswa-sisiwi di SMA kota Sidoarjo di dapatkan karakteristik sebagai berikut:

Tabel 1. Karakteristik responden atau siswasiswi SMA di Kota Sidoarjo $(n=350)$

\begin{tabular}{ccc}
\hline \multicolumn{1}{c}{ Variabel } & Frekuensi (n) & Presentase (\%) \\
\hline Usia & & \\
14 tahun & 1 & 0,3 \\
15 tahun & 52 & 17 \\
16 tahun & 219 & 71,8 \\
17 tahun & 30 & 9,8 \\
\hline
\end{tabular}

\begin{tabular}{ccc}
18 tahun & 2 & 0,7 \\
19 tahun & 1 & 0,3 \\
\hline kelas & 178 & \\
X & 82 & 58,4 \\
XI & 45 & 26,9 \\
XII & & 14,8 \\
\hline Jenis kelamin & 221 & 72,5 \\
Perempuan & 84 & 27,5 \\
Laki-laki &
\end{tabular}

Berdasarkan tabel 1. Menjelaskan bahwa karakteristik responden pada distribusi usia terbanyak adalah usia 16 tahun. Pada distribusi kelas terbanyak adalah kelas $\mathrm{X}$ (sepuluh) dan pada distribusi jenis kelamin terbanyak adalah perempuan.

Tabel 2. Distribusi frekuensi berdasarkan persepsi dan stigma siwa-siswi terhadap penyandang disabilitas di SMA kota Sidoarjo $(\mathbf{n}=\mathbf{3 5 0})$

\begin{tabular}{lcc}
\hline \multicolumn{1}{c}{ Variabel } & $\begin{array}{c}\text { Jumlah } \\
(\mathbf{n})\end{array}$ & $\begin{array}{c}\text { Prosentase } \\
(\boldsymbol{\%})\end{array}$ \\
\hline Persepsi & & \\
Baik & 242 & 79,3 \\
Buruk & 63 & 20,7 \\
\hline Stigma & & \\
Rendah & 244 & 80 \\
Tinggi & 61 & 20 \\
\hline
\end{tabular}

Berdasarkan hasil tabel 2. Menunjukkan bahwa distribusi frekuensi berdasarkan persepsi dan stigma siswa-siswi terhadap penyandang disabilitas di SMA Kota Sidoarjo adalah memiliki persepsi baik terhadap penyandang disabilitas sedangkan responden juga memiliki stigma yang rendah terhadap penyandang disabilitas di SMA kota Sidoaro.

Tabel 3. Analisis hubungan persepsi dan stigma penyandang disabilitas pada siswa-siswi di SMA Kota Sidoarjo

\begin{tabular}{|c|c|c|c|c|c|}
\hline \multirow[b]{3}{*}{ Persepsi } & \multicolumn{4}{|c|}{ Stigma } & \multirow[b]{2}{*}{ p-Value } \\
\hline & \multicolumn{2}{|c|}{ Rendah } & \multicolumn{2}{|c|}{ Tinggi } & \\
\hline & $\mathrm{n}$ & $\%$ & $\mathrm{n}$ & $\%$ & \multirow{4}{*}{0,001} \\
\hline Baik & 204 & 83,6 & 38 & 15,7 & \\
\hline Buruk & 40 & 63,5 & 23 & 36,5 & \\
\hline Total & 244 & 80,0 & 61 & 20,0 & \\
\hline
\end{tabular}

Tebel 3. Menjelaskan bahwa terdapat hubungan persespi dengan stigma penyandang disabilitas pada siswa-siswi di SMA kota Sidoarjo. Hasil penelitian menunjukkan bahwa responden memiliki persespi baik terhadap penyandang disabilitas. Persepsi tentang masalah kesehatan di pengaruhi erat dengan 
perilaku pencarian kesehatan(Alfianto \& Safitri, 2019). Persepsi responden tentang kesehatan khususnya terhadap seseorang dengan penyandang disabilitas di pangaruhi oleh lingkungan sekolah. Penelitian di Negara Nigeria menyebutkan bahwa mahasiswa mampu menggunakan fasilitas kesehatan dengan baik salah satunya di pengaruhi oleh persepsi dari mahasiswa (Onyeneho et al., 2016).

Selain itu juga penelitian yang dilakukan oleh Sandi et al., (2020) menyatakan bhawa persepsi masyarakat tentang penggunaan fasilitas kesehatan di pengaruhi oleh fasilitas kesehatan yang memadai sehingga masyarakat memiliki persepsi yang baik terhadap fasilitas dan pelayanan kesehatan tersebut.

Selain itu juga pada variabel stigma terhadap penyandang disabilitas disebutkan bahwa stigma pada responden tersebut sangat rendah. Hal tesebut sejalan dengan penelitian tentang stigma gangguan jiwa. Stigma pada orang dengan gangguan jiwa di masyarakat di pengaruhi oleh beberapa faktor sepereti otoritas, kebijakan, pembatasan sosial, prinsip pada komunitas kesehatan serta stigma terhadap orang ganggun jiwa (Purnama, 2016), selain itu juga stigma pada diri juga muncul akibat pengetahuan yang kurang terhadap suatu objek serta persepsi dari diri sendiri (Maharani, 2017).

Hubungan antara persepsi dan stigma penyandang disabilitas pada siswa-siswi di SMA Kota Sidoarjo menunjukkan terdapat hubungan yang signifikan. Hal tersebut di pengaruhi beberapa faktor disekolah tersebut seperti fasilitas sekolah terhadap penyandang disabilitas (Soebiantoro, 2017). Fasilitas sekolah salah satunya terdapat layanan kesehatan. Model layanan kesehatan yang dapat di kembangkan di sekolah adalah dengan mengembangkan unit kesehatan sekolah.

Unit kesehatan sekolah di harapkan mampu mengatasi masalah kesehatan tidak hanya kesehatan fisik namun juga kesehatan mental bagi siswa dan penyandang disabilitas melalui pendidikan kesehatan seperti psikoedukasi pada siswa (Alfianto et al., 2019) dan juga melalui pencegahan pemberian pertolongan pertama kesehatan mental diharapkan mampu mengurangi persepsi buruk dan stigma negatif pada siswa baik yang sehat ataupun menyandang disabilitas (Candra et al., 2020).

\section{KESIMPULAN}

Karakteristik responden di dominasi oleh siswa dari usia 16 tahun, berada di kelas X (sepuluh) dan berjenis kelamin perempuan. Sedangkan pada penelitian ini terdapat hubungan antara persepsi dengan stigma penyandang disabilitas pada siswa-siswi di SMA Kota Sidoarjo.

\section{UCAPAN TERIMA KASIH}

Kami ucapkan terima kasih kepada kepala sekolah SMA di Kota Sidoarjo yang telah memberikan tempat untuk penelitian kami serta seluruh responden siswasiswi SMA di Kota Sidoarjo yang telah berpatisipasi dalam penelitian ini.

\section{DAFTAR RUJUKAN}

Alfianto, A. G., Apriyanto, F., \& Diana, M. (2019). Pengaruh Psikoedukasi Terhadap Tingkat Pengetahuan Tentang Stigma Gangguan Jiwa. JI-KES (Jurnal Ilmu Kesehatan), 2(2), 37-41. https://doi.org/10.33006/ji-kes.v2i2.117

Alfianto, A. G., \& Safitri, A. (2019). Efikasi Diri Siswa dengan Tanda Gejala Psikosis Awal dalam Mencari Bantuan Melalui Usaha Kesehatan Sekolah Jiwa. JI-KES (Jurnal Ilmu Kesehatan), 3(1), 7-11. https://doi.org/10.33006/ji-kes.v3i1.123

Aydin, A. (2015). A Comparison of the Alexithymia, Self-compassion and Humour Characteristics of the Parents with Mentally Disabled and Autistic 
Children. Procedia - Social and Behavioral Sciences, $\quad 174, \quad 720-729$. https://doi.org/10.1016/j.sbspro.2015.01.607

Candra Aprilia Kartika, Ahmad Guntur Alfianto, Mizam Ari. K. (2020). Pertolongan pertama kesehatan jiwa pada siswa dengan masalah psikososial yang berisiko bunuh diri. Jurnal Ilmu Keperawatan Jiwa, 3(2), 161-172. https://doi.org/http://dx.doi.org/10.32584/jikj.v3 i2

Caqueo-Urízar, A., Urzúa, A., Loundon, A., Boucekine, M., Fond, G., \& Boyer, L. (2019). The latin american version of the internalized stigma of mental illness scale (la-ismi): A multicentric validation study from three latin american countries. Health and Quality of Life Outcomes, $\quad 17(1), \quad 1-10$. https://doi.org/10.1186/s12955-019-1238-2

Coston, B. M. (2019). Disability, sexual orientation, and the mental health outcomes of intimate partner violence: A comparative study of women in the U.S. Disability and Health Journal, 12(2), 164-170.

https://doi.org/10.1016/j.dhjo.2018.11.002

Fauth, R. C., Platt, L., \& Parsons, S. (2017). The development of behavior problems among disabled and non-disabled children in England. Journal of Applied Developmental Psychology, 52(June 2016), 46-58. https://doi.org/10.1016/j.appdev.2017.06.008

Jakobsson, M., Josefsson, K., Jutengren, G., Sandsjö, L., \& Högberg, K. (2019). Sleep duration and sleeping difficulties among adolescents: exploring associations with school stress, selfperception and technology use. Scandinavian Journal of Caring Sciences, 33(1), 197-206. https://doi.org/10.1111/scs.12621
Kementerian Kesehatan RI Badan Penelitian dan Pengembangan. (2018). Hasil Utama Riset

Kesehatan Dasar. Kementrian Kesehatan Republik Indonesia.

Krupchanka, D., Chrtková, D., Vítková, M., Munzel, D., Čihařová, M., Růžičková, T., Winkler, P., Janoušková, M., Albanese, E., \& Sartorius, N. (2018). Experience of stigma and discrimination in families of persons with schizophrenia in the Czech Republic. Social Science and Medicine, 212 , 129-135. https://doi.org/10.1016/j.socscimed.2018.07.01 5

Löve, L., Traustadóttir, R., \& Rice, J. G. (2018). Trading autonomy for services: Perceptions of users and providers of services for disabled people in Iceland. Alter, 12(4), 193-207. https://doi.org/10.1016/j.alter.2018.04.008

Maharani, F. (2017). Faktor -Faktor Yang Berhubungan Dengan Stigma Terhadap Orang Dengan Hiv Dan Aids (Odha). Jurnal $\begin{array}{lll}\text { Endurance, } & 2(2), & 158 .\end{array}$ https://doi.org/10.22216/jen.v2i2.1300

Onyeneho, N. G., Amazigo, U. V., Njepuome, N. A., Nwaorgu, O. C., \& Okeibunor, J. C. (2016). Perception and utilization of public health services in Southeast Nigeria: Implication for health care in communities with different degrees of urbanization. International Journal for Equity in Health, 15(1), 1-11. https://doi.org/10.1186/s12939-016-0294-z

Purnama. (2016). Gambaran Stigma Masyarakat Terhadap Klien. Jurnal Pendidikan Keperawatan Indonesia, 2(1), 29-37. file:///C:/Users/user/Downloads/2850-5242-1PB (1).pdf\%0A\%0A

Sandi, P. L., Bratajaya, C. N. A., \& Susilo, W. H. 
(2020). Faktor yang berhubungan dengan intensi masyarakat untuk berobat ke pelayanan kesehatan. 7(1), 1-7.

Soebiantoro, J. (2017). Pengaruh Edukasi Kesehatan Mental Intensif Terhadap Stigma pada Pengguna Layanan Kesehatan Mental. INSAN Jurnal Psikologi Dan Kesehatan Mental, 2(1), 1. https://doi.org/10.20473/jpkm.v2i12017.1-21
Yaqien, S. H., Raharjo, S. T., \& Gutama, A. S. (2018). Kekuatan Mahasiswa Berwirausaha: Kasus Di Universitas Padjadjaran. Share: Social Work Journal, $8(1)$ 127. https://doi.org/10.24198/share.v8i1.18100

Cite this article as: Permatasari, Dian. dkk.(2020). Persepsi Dan Stigma Penyandang Disabilitas Pada Siswa-Siswi Sekolah Menengah Atas. Media Husada Journal of Nursing Science. Vol. 1 (No.1), 73-78. https://doi.org/10.33475/mhjns.vdiisi tim redaksi. 